\title{
How fast should nanotechnology advance?
}

To the Editor - New technologies are often met with apprehension and criticism. It is therefore essential that all sides of the nanotechnology debate be aired, as is pointed out in the promising introduction to the article "What drives public acceptance of nanotechnology" by Currall and co-workers ${ }^{1}$. However, the article by Currall et al. also embodies an unquestioned assumption that the technology should advance. They believe that research will progress unhindered as long as we "educate the public aggressively with facts about the risks and benefits of nanotechnology". We believe this position reflects a failure to learn from the experiences of other innovative technologies, and that, ultimately, it may provoke public resistance to safe and beneficial developments in nanotechnology.

It is well established that all people, including experts, imbue risk analyses with personal values ${ }^{2-4}$. Scientists involved in the communication of new technologies often steer the debate in a purely technical direction, alienating an already sceptical audience ${ }^{5}$. This propensity carries an assumption that scientists can obtain 'objective facts' about risks and benefits that are yet to unfold. Scientists directly involved in new advances are sometimes slow to understand and acknowledge public concerns.

Educating the public will not necessarily solve the problem of public acceptance. Flaws with this 'cognitive deficit' model of public understanding and acceptance of science have been exposed in high-profile cases, such as the GM food and nuclear energy debates ${ }^{6}$. The model ignores the inherent uncertainty and subjectivity of risk assessments, and takes a narrow view of what is at stake. Risk analyses often ignore social and economic issues. As a result, the public may perceive risks as unethical or unacceptable, generating unexpected, broad-based resistance to innovation. Public trust in the nanoindustry may be further eroded by findings of recent research ${ }^{7}$ that suggests "a substantial number of [industry] companies have no structured approach for assessing the risks associated with nanoparticulate material".

The motives of governments and businesses who invest in new technology are not always compatible with those of broad sectors of the public. For example, companies and universities are patenting new technological innovations early and often, and nanotechnology is no exception $^{8}$. The capture of intellectual property in this fashion may have important, unacknowledged social and economic consequences. Innovations such as a carbon nanofibre replacement for cotton may survive an environmental risk assessment, but may damage cottongrowing communities in developing economies. Moreover, breakthroughs in nanotechnology are owned by a small handful of companies, largely or exclusively based in developed economies.

Many researchers, including Currall et al., and many policy makers are concerned that a lack of public acceptance will hinder developments in nanotechnology. Yet advances in nanotechnology already proceed ahead of the policy and regulatory environment ${ }^{9}$. Therefore, it is probable that for a broader society to be comfortable with innovations in nanotechnology, progress may be slower than scientists would like. Scientists may be delayed by social deliberation.

Scientific research can be insensitive to the concerns of the community. Scientific culture is structured to give rewards to those who achieve breakthroughs first. In this race, the risks are evaluated most often by people who have a stake in the outcome. These same people are unlikely to represent fairly the philosophies, opinions and values of all those who bear the burden of the risks of innovation. Furthermore, the level of risk that we are prepared to tolerate varies dramatically from person to person. Nanotechnology promises products and solutions so advanced that they seem like science fiction, and people are understandably hesitant to dive headfirst into a world where they relinquish control over unforeseen consequences, irrespective of the benefits. Although nanotechnology will undoubtedly yield remarkable benefits, social concerns will not simply dissolve by aggressively educating the public about the science. The discipline should embrace a broader view of public involvement in research, particularly in the evaluation of its risks and benefits.

\footnotetext{
Bonnie Wintle*, Mark Burgman and Fiona Fidler

Australian Centre of Excellence for Risk Analysis, School of Botany, University of Melbourne, Victoria 3010, Australia

*e-mail:b.wintle@pgrad.unimelb.edu.au
}

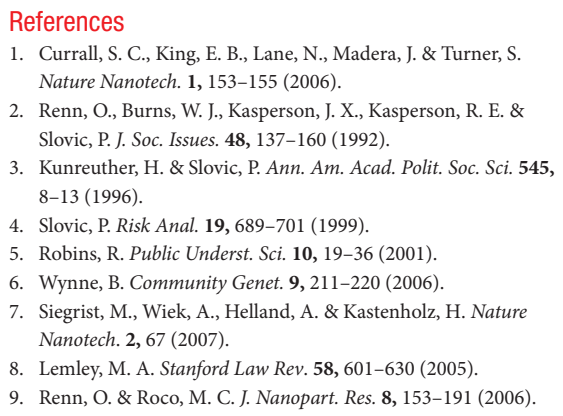

Authors' response - Wintle, Burgman and Fidler ${ }^{1}$ raise several thoughtful points regarding public education about nanotechnology, public acceptance and the advancement of nanotechnology in general. However, we maintain our view that nanotechnology must advance. Indeed, both the science and the commercialization of nanotechnology is already advancing at a rapid pace and, unlike Wintle et al., we believe that questioning whether nanotechnology should advance is not a fruitful line of debate. The more interesting debate concerns how it should advance and at what pace.

Should public exposure to nanotechnology be allowed to proceed without government regulation or informed public debate about risks, benefits and ethical concerns? We think not and believe that this is the domain where intellectual and governmental policy debates should take place. Wintle et al. are correct to note the possible discrepancy between how scientists and members of the public perceive risks and benefits of nanotechnology. This was precisely why we conducted the first large-scale studies of how the public compares the risks and benefits associated with nanotechnology with those associated with other technologies, as well as how the public reacts to the risks and benefits of new commercial products containing nanotechnology ${ }^{2}$. Four of us (S.C.C., E.B.K., J.M., and S.T.) are behavioural scientists, so we are mindful of differences between the psychology of the layperson versus the scientific expert.

For this reason we conducted our surveys of citizens rather than scientists. Furthermore, given the number of previous surveys of public perceptions of the general field of nanotechnology $y^{3,4}$, we asked our survey respondents to assess the risks and benefits of specific products containing nanotechnology. As consumers, members of the public 
are well equipped to consider the risks and benefits of actual products 5 , but they are less well suited to making decisions about abstract scientific concepts such as nanotechnology. Moreover, the focus of the previous studies was too far removed from the predictors of actual citizens' behaviour to be of much use to policy makers or business managers. Policy makers will be better informed by research that focuses on tangible commercial products, and how the perceived risks and benefits associated with these products will drive actual behaviour.

Risks and benefits can be described as 'distal' or 'proximal'. For the typical member of the public, the science of nanotechnology involves only distal risks and benefits (that is, those that may happen in the future and/or to someone else). However, when asked about commercial products containing nanotechnology, the risks and benefits are much more proximal (that is, more tangible, immediate, and personal).

We agree with Wintle et al. that "the discipline [nanotechnology] should embrace a broader view of public involvement in research, particularly in the evaluation of its risks and benefits". We do not take the stance that simply educating the public about the science of nanotechnology will lead to public acceptance. As stated in our original article $^{2}$, we continue to advocate that “interagency 'societal impact' subgroups can be formed to coordinate education and public outreach efforts by creating a clearing house in each country that synthesizes information about the health and environmental impacts of nanotechnology, including performance indicators and the latest scientific findings on risks and benefits".

Contrary to the claim by Wintle et al. that we suggested nanotechnology should advance without public involvement, our article aimed to lay the foundation for a broad-based debate about the future of nanotechnology by highlighting the importance of public perception. Governmental and business leaders must push for greater understanding of possible risks while simultaneously being responsible in exploring how nanotechnology can be used in products that may have dramatic societal benefits. We must urge governmental regulators and business leaders to develop comprehensive and thorough sources of information about nanotechnology products and distribute that information accordingly. Armed with solid information, consumers will make their own responsible decisions about using commercial products containing nanotechnology.

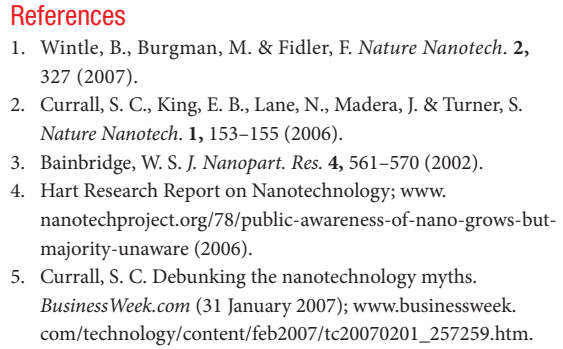

1. Wintle, B., Burgman, M. \& Fidler, F. Nature Nanotech. 2 , 327 (2007).

2. Currall, S. C., King, E. B., Lane, N., Madera, J. \& Turner, S. Nature Nanotech. 1, 153-155 (2006).

3. Bainbridge, W. S. J. Nanopart. Res. 4, 561-570 (2002).

4. Hart Research Report on Nanotechnology; www. nanotechproject.org/78/public-awareness-of-nano-grows-butmajority-unaware (2006)

5. Currall, S. C. Debunking the nanotechnology myths. BusinessWeek.com (31 January 2007); www.businessweek. com/technology/content/feb2007/tc20070201_257259.htm.

\section{Acknowledgements}

The research discussed in this correspondence was supported in part by the National Science Foundation (award numbers EEC-0118007 and SES-0531146)

Steven C. Currall ${ }^{1,2 *}$, Eden B. King ${ }^{3}$, Neal Lane ${ }^{4}$, Juan Madera ${ }^{5}$ and Stacey Turner ${ }^{1}$ Faculty of Engineering Sciences, University College London, London WC1E 6BT, UK

${ }^{2}$ London Business School, London NW1 4SA, UK ${ }^{3}$ Department of Psychology, George Mason University, Fairfax, Virginia 22030, USA

${ }^{4}$ Department of Physics and Astronomy and Baker Institute for Public Policy, Rice University, Houston, Texas 77005, USA

${ }^{5}$ Department of Psychology, Rice University,

Houston, Texas 77005, USA

*e-mail:scc@ucl.ac.uk
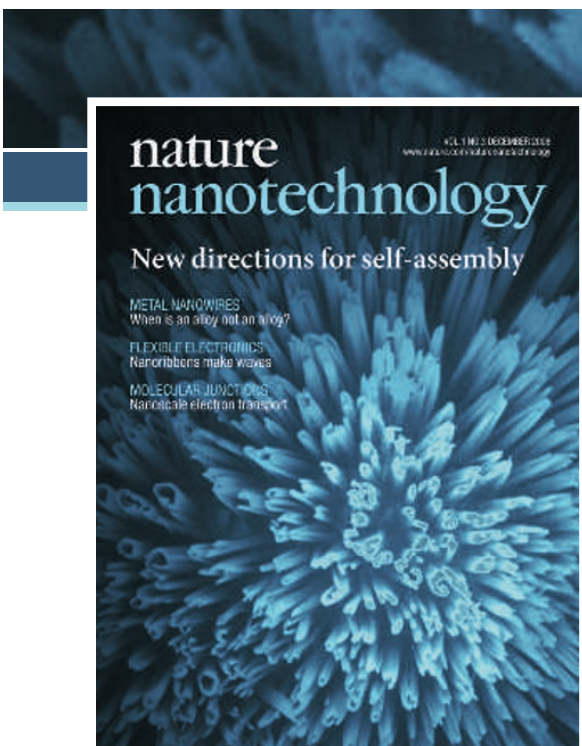

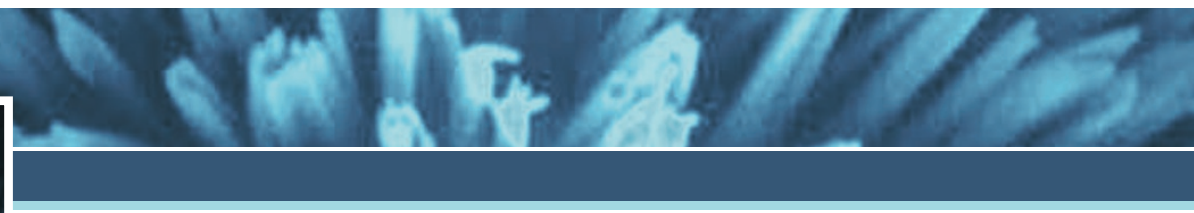

\section{Call for correspondence}

Nature Nanotechnology invites readers to submit correspondence on all areas of nanoscience and nanotechnology. The Correspondence section will publish letters on topics that are of widespread interest to the community, as well as letters that comment on articles published in the journal. The emphasis is on brevity (less than 500 words), topicality and widespread interest, and letters may be edited. References, if necessary, should be restricted to ten or fewer.

Correspondence should be addressed to the Editor at naturenano@nature.com

Visit www.nature.com/nnano/authors/article_types/index.html for more details 